\title{
Measuring time accessibility and its spatial characteristics in the urban areas of Beijing
}

\author{
WANG Jianghao ${ }^{1,2}$, DENG Yu", ,SONG Ci", "TIAN Dajiang ${ }^{3,4}$
}

1. Institute of Geographic Sciences and Natural Resources Research, CAS, Beijing 100101, China;

2. Jiangsu Center for Collaborative Innovation in Geographical Information Resource Development and Application, Nanjing 210023, China;

3. The Postdoctoral Research Station of Tourism Information Research Center, Beijing Union University \& University of International Business and Economics, Beijing 100029, China;

4. School of Information Technology and Management, University of International Business and Economics, Beijing 100029, China

\begin{abstract}
Construction of road infrastructure is fundamental to city operation and development, as well as an important pathway and focus in physical urban-rural integration. The long-term implementation of a system of ring roads plus radiating roads in Beijing has strongly impacted urban infrastructure construction and space-time accessibility. Particularly, recent rapid growth of private car ownership in Beijing has imposed greater loads on its road system, seriously hampering urban commuting efficiency and negatively impacting quality of life. To address such challenges and enhance the rapid development of transport infrastructure, Beijing has accelerated rail transit construction since 2008 in an effort to improve commuting capacity. This paper aims to measure time accessibility and its spatial characteristics in urban areas of Beijing by applying a comprehensive method that combines vector and raster attribute data generated from road network and subway transport infrastructure. By using a dual index of accessibility and road density, the study further reveals the features of and differences in spatial accessibility and the construction of road systems in urban areas of the northern and southern parts of Beijing. The findings of this study can provide a scientific basis for future urban planning and road system construction both in general and with respect to Beijing, given its aspirations to become a world city.
\end{abstract}

Keywords: accessibility; road density; spatial characteristics; Beijing

Received: 2015-07-15 Accepted: 2015-09-09

Foundation: National Natural Science Foundation of China, No.41601164, No.41601427; Key Program of National Natural Science Foundation of China, No.71433008; Cultivate Project of Institute of Geographic Sciences and Natural Resources Research, CAS, No.TSYJS03

Author: Wang Jianghao, PhD and Assistant Professor, specialized in spatio-temporal data mining, geostatistics and GIS. E-mail: wangjh@1reis.ac.cn

*Corresponding author: Song Ci, PhD and Assistant Professor, specialized in GIS. E-mail: songci@igsnrr.ac.cn Tian Dajiang, PhD, specialized in tourism geography. E-mail: tiandj.08b@igsnrr.ac.cn 


\section{Introduction}

Transportation accessibility describes the degree of convenience of travel from one location to another, and involves measuring the closeness of markets, the comprehensiveness of an economy, and access to places of employment ( $\mathrm{Li}$ and $\mathrm{Lu}, 2001$ ). Current research on traffic accessibility has focused on its assessment, accessible spatial patterns and their evolution, the influence of accessibility on the development of the regional economy. Research has also focused on high-speed road networks (Dupuy and Stransky, 1996; Li and Shum, 2001), city ring roads (Linneker and Spence, 1996), railway networks (Murayama, 1994; Gutiérrez et al., 1996; Jin and Wang, 2004; Wei and Cong, 2004), aviation infrastructure (Bowen, 2000), and city or regional road networks (Cao and Yan, 2003; Zhang and Lu, 2006; Lie and Shao, 2008, Jin et al., 2009). The city discussed in the present study, Beijing, has a high-speed road network, city ring roads, subway and aviation networks, and both city and regional road networks. The main measurement index applied to traffic accessibility is transportation cost (namely, the factors hindering movement between two points), which has three main aspects: distance (Keeble et al., 1988), time (Lutter et al., 1992; Bruinsma 1993; Geertman et al., 1995; Gutiérrez and Urbano, 1996) and general transportation cost (Linneker and Spence, 1992; Spence and Linneker, 1994). When attempting to simulate or approximate reality as well as considering maneuverability, scholars mainly choose time as the index of measuring traffic accessibility (Gutiérrez, 2001). While many studies discuss lack of accessibility, few analyze the socioeconomic factors that influence the distribution of accessibility. Moreover, few studies use regional heterogeneity analysis and a comprehensive analysis of transportation infrastructure to generate the time accessibility and spatial difference.

Based on the above considerations, this paper measures time accessibility within the Sixth Ring Road of Beijing by integrating raster and vector data. It then applies isochronal methods to comprehensively analyze the accessibility and spatial characteristics of Beijing's regional road network, and identifies the basic relationships between the city expressway and the accessibility features of Beijing. Finally, based on the density evaluation of the township zoning road, the use of the double index of accessibility and road density further reveals the features of spatial accessibility and road infrastructure construction, as well as their different levels of prevalence in the northern and southern parts of the city. A zoning study is also performed on township-level divisions within the urban area of Beijing. Based on the time accessibility, we analyzed regional land use and the relationships between regional land use efficiency and location factors in each type of land use since 2008. We also identified the regional difference in location factors, to provide a scientific basis for future urban planning and road system construction for Beijing Municipality.

\section{Research areas and methods}

\subsection{Study area}

The study area comprises a total of 162 street (township) units in eight core functional areas and functional development districts in the municipality of Beijing as well as urban parts of Tongzhou, Changping and Shunyi (all suburban districts of Beijing) (Figure 1). For convenience of analysis, this study adopted the old administrative divisions of Beijing and divides 
the study area into two main parts, the northern urban area (NUA) and the southern urban area (SUA) with the Line 1 subway serving as the dividing line (in administrative terms, the core area of Beijing currently comprises Dongcheng, Xicheng, Xuanwu and Chongwen, see Figure 1). This division is not only consistent with the basic understanding of the traditional geographical scope of Beijing, but can also help identify regional differences in accessibility and infrastructure.

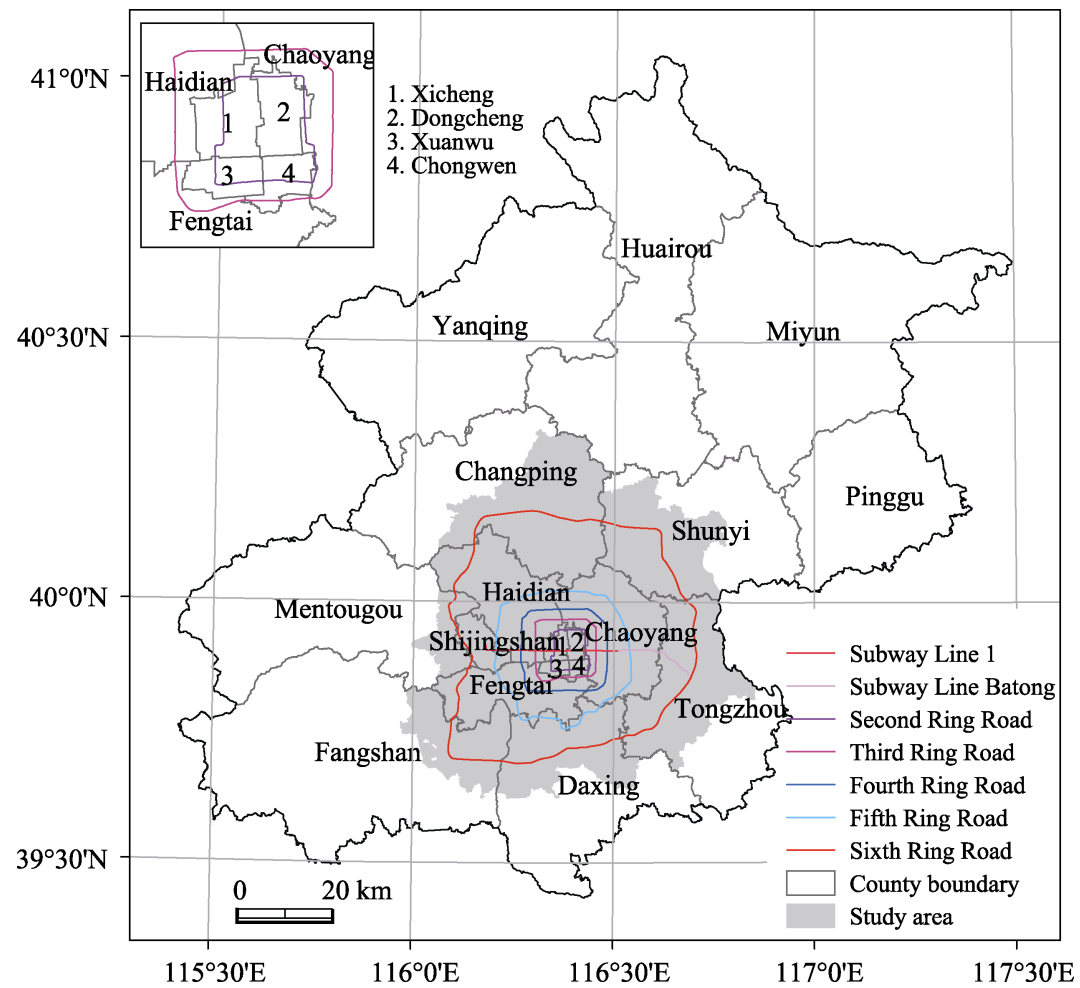

Figure 1 Location of the study area in Beijing

\subsection{Data sources}

The road system of Beijing can be divided into expressways, arterial roads, secondary roads and branch roads (Reng et al., 2003), the city expressways and arterial roads bear most of the city's road traffic load. To describe accessibility in a global city, our study also considers the influence of the subway on commuting in Beijing. Because of the particularity of the subways, vector data and other road data are used together. Finally, we obtained a spatial pattern map of accessibility in Beijing based on the two accessibility evaluation results.

Regarding different road speed standards, Beijing's heavy traffic necessitates a comprehensive evaluation of road transport attributes: that is, both rush hour and non-rush hour traffic should be evaluated, compared, and comprehensively considered. Analysis of Beijing Traffic and Economic Operations for 2007 reported average road speeds in Beijing during peak times. Within the Fifth Ring Road, during morning rush hour the average speed for expressways was $31.2 \mathrm{~km} / \mathrm{h}$ while that for trunk roads was $20.5 \mathrm{~km} / \mathrm{h}$. During the evening rush hour, the average speed for expressways and trunk roads was 26.7 and $18.4 \mathrm{~km} / \mathrm{h}$, respectively. The average speeds for all road types during outside of rush hour were as follows: 
expressways, $70 \mathrm{~km} / \mathrm{h}$; arterial roads, $50 \mathrm{~km} / \mathrm{h}$ (Xu et al., 2008); and state roads, $60 \mathrm{~km} / \mathrm{h}$ (Yang et al., 2004). This paper calculated overall road speed as the average of rush hour and non-rush hour road speeds (Table 1).

Table 1 Road speed for different road types

\begin{tabular}{|c|c|c|c|c|c|c|}
\hline \multirow{2}{*}{$\frac{\text { Road type }}{\text { Running attribute }}$} & \multicolumn{2}{|c|}{ Expressways } & \multicolumn{2}{|c|}{ Arterial roads } & \multicolumn{2}{|c|}{ State roads } \\
\hline & Peak & Non-peak & Peak & Non-peak & Peak & Non-peak \\
\hline Average speed (km/h) & 28.95 & 70 & 19.45 & 50 & 19.45 & 60 \\
\hline Weighted average speed $(\mathrm{km} / \mathrm{h})$ & \multicolumn{2}{|c|}{49.475} & \multicolumn{2}{|c|}{34.725} & \multicolumn{2}{|c|}{39.725} \\
\hline
\end{tabular}

The designed maximum speed of Beijing's subway trains ranges from 100 to $140 \mathrm{~km} / \mathrm{h}$ (Shi et al., 2003), but the speed of actual operations generally does not exceed $80 \mathrm{~km} / \mathrm{h}$ (Nong, 2003). In this paper, with the help of the inquiry function for subway lines and time provided by the website (www.go2map.com), we randomly selected the initial and terminal stations of different subway lines and obtained related routes and associated travel times. Finally, we obtained the average speed of the subway lines. As shown in Table 2, the average speed of the subways is $31.31 \mathrm{~km} / \mathrm{h}$.

Table 2 Subway speeds with different lines

\begin{tabular}{|c|c|c|c|c|c|c|}
\hline Subway line & Starting point & Destination & $\begin{array}{l}\text { Distance } \\
(\mathrm{km})\end{array}$ & $\begin{array}{l}\text { Time } \\
(\mathrm{min})\end{array}$ & $\begin{array}{l}\text { Average speed } \\
(\mathrm{km} / \mathrm{h})\end{array}$ & $\begin{array}{l}\text { Average speed of } \\
\text { subway }(\mathrm{km} / \mathrm{h})\end{array}$ \\
\hline Subway Line 5 & Tiantongyuanbei & Songjiazhuang & 27.3 & 54 & 30.33 & \multirow{9}{*}{31.31} \\
\hline Subway Line 10 & Bagou & Jingsong & 23.8 & 50 & 28.56 & \\
\hline Subway Line 13 & Xizhimen & Lishuiqiao & 25.1 & 39 & 38.61 & \\
\hline Subway Line 8 & $\begin{array}{l}\text { South Gate of } \\
\text { Forest Park }\end{array}$ & Beitucheng & 3.7 & 11 & 20.18 & \\
\hline Subway Line 4 & Anheqiaobei & Gongyiqiaoxi & 27.4 & 56 & 29.35 & \\
\hline Subway Line 2 & Xizhimen & Qianmen & 7.9 & 19 & 24.94 & \\
\hline Subway Line 1 & Pinguoyuan & Sihui & 28.6 & 55 & 31.2 & \\
\hline Subway Line Batong & Sihui & Tuqiao & 18.1 & 35 & 31.02 & \\
\hline Airport Line & Sanyuanqiao & Hangzhanlou & 25.4 & 32 & 47.62 & \\
\hline
\end{tabular}

Additionally, the study considers the influence of urban public space on road time cost, and sets the grid range time cost of public spaces (such as parks and green spaces) to $1 \mathrm{~h}$, as they may be considered obstacle spaces. The speed for other blank areas (such as spaces without roads and barrier free spaces) is set to $10 \mathrm{~km} / \mathrm{h}$ and spatial data is obtained from the 2012 road traffic map (Figure 2). The traffic map is generated by matching the road map from the Beijing City Master Plan (2004-2020) with maps from Google Earth (using images registered in December 2012) and digitalizing the result.

\subsection{Time accessibility measurement}

To calculate the regional wide comprehensive accessibility of the full space and take into account the jumping operation mode of the subways, this paper adopts a combination of network analysis and cost-weighted distance analysis (Jiang et al., 2010). The specific method is as follows:

(1) Generate a road raster map with subway station information. Specify the center, also known as the source, $o$. 


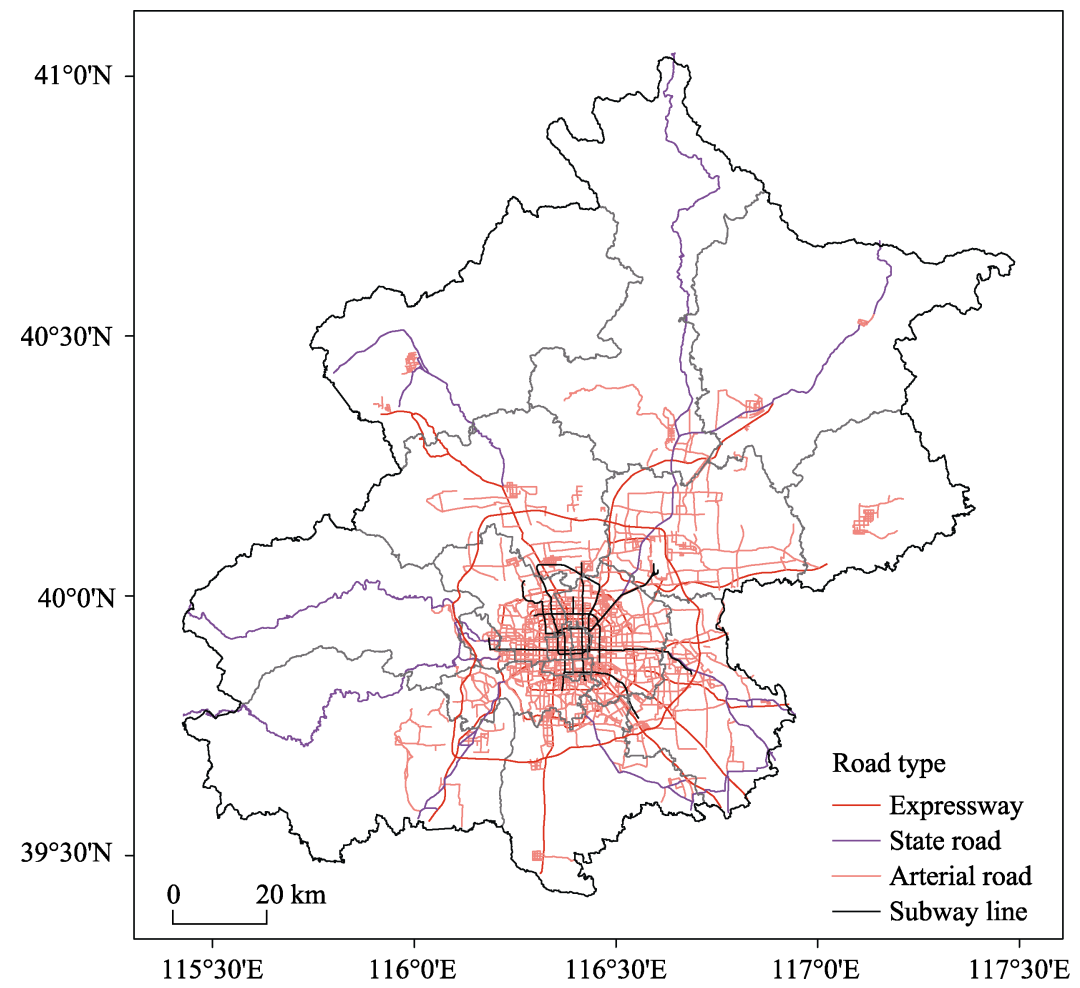

Figure 2 Map showing the arterial roads of Beijing in 2012

(2) Based on the analysis of the cost-distance algorithm, the time cost $t_{o p}$ of computing the route from the center to any point $p$, namely time $A_{o i}$, is calculated for a subway station $i$.

(3) Through network analysis, calculate the shortest time distance $B_{i j}$ from one site to other sites.

(4) After the calculation on the subway, the shortest time $C_{o i}$ was calculated between the central point to each subway station. The specific method is as follows: first, identify the point closest to the center (site 1), and put it into the sequence $R=\left\{C_{o 1}\right\}$ where $C_{o 1}=A_{o 1}$. Then find the next closest point to the center (site 2), compare the $A_{o 2}$ of this site and the shortest time between all the sites and this site by network analysis, $B_{12}+C_{o 1}$, then solve the smaller time distance and include it in the sequence $R=\left\{C_{o 1}, C_{o 2}\right\}$. Find the third nearest site, that is, $C_{o 3}=\min \left\{A_{o 3}, B_{13}+C_{o 1}, B_{23}+C_{o 2}\right\}$. Continue applying this method until the shortest times to the center have been determined for all sites.

(5) Calculate the grid time cost of travel from each subway station to the full space and the time costs for travel from corresponding points to the full space, and get $N$ diagram layer: $E_{1}, E_{2}, \ldots, E_{N}$, and $T_{1 p}, T_{2 p}, \ldots, T_{N p}$, respectively.

(6) Calculate the shortest travel time between the center and all of the empty points $T_{o p}$. That is, $T_{o p}=\min \left\{t_{o p}, t_{1 p}+C_{o 1}, t_{2 p}+C_{o 2}, \cdots, t_{N p}+C_{o N}\right\}$.

\section{Results and analysis}

\subsection{The basic characteristics of space accessibility}

From time accessibility map of various streets in urban areas of Beijing (Figure 3), there is 
an obvious trend whereby accessibility decreases with increasing distance from the center. However, traffic exerted a varying effect on changes in accessibility. The NUA has better accessibility than the SUA. This is mainly because of the densely distributed subway line in the north. Taking the core area as an example, Dongcheng (eastern) and Xicheng (western) have the highest accessibility, with average accessibility values of 0.22 and $0.23 \mathrm{~h}$. In contrast, though Chongwen and Xuanwu are also in the core area with good accessibility, their scores were lower than those for the eastern and western parts of the city, with average accessibility values of 0.24 and $0.28 \mathrm{~h}$, respectively. Overall, the NUA stretches further outward than the SUA, and the accessibility time is the same for both regions. Additionally, in the SUA, accessibility degree varied with traffic. For example, influenced by subways Line 4 and Line 5 , the accessibility of the SUA is affected by the streets (same as townships) extending from places superior to those around them.

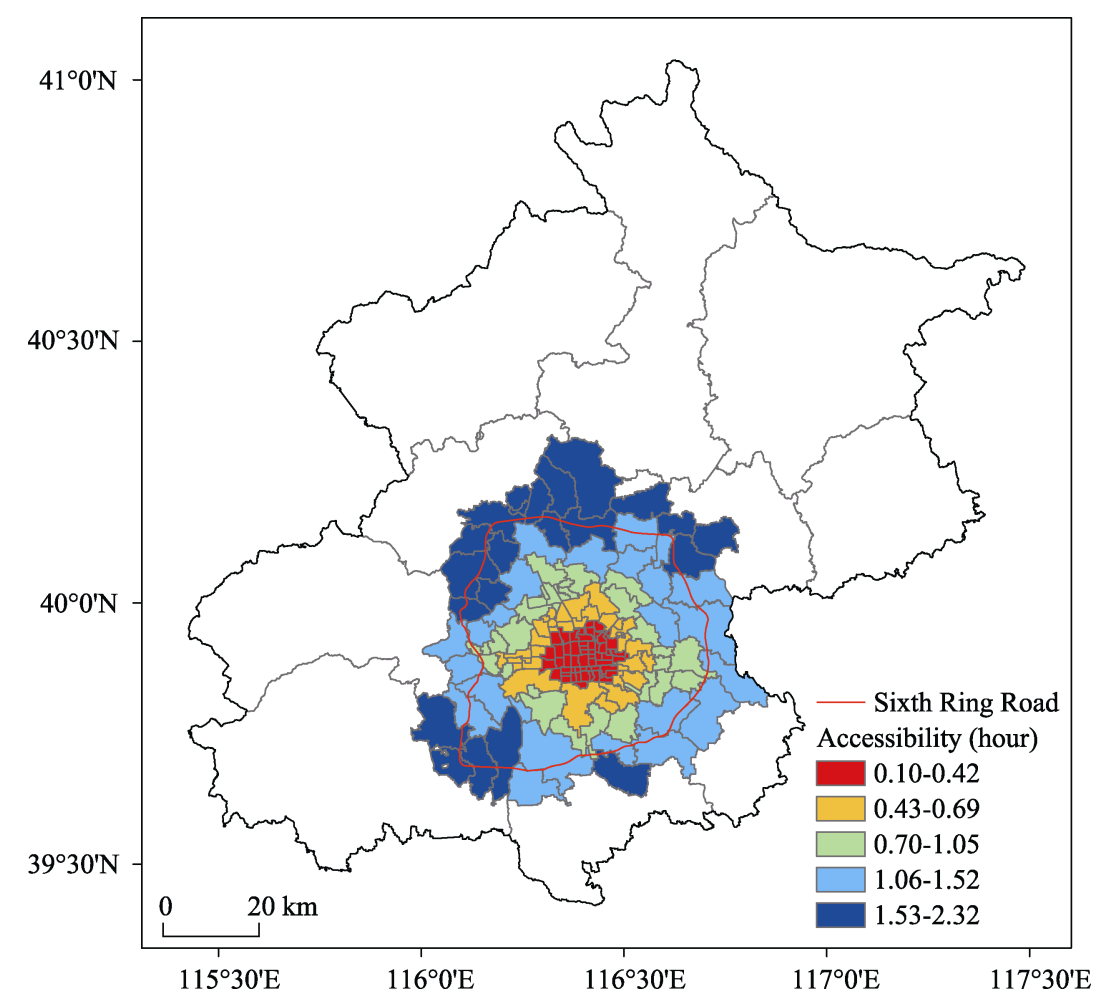

Figure 3 Map showing time accessibility in the study area of Beijing in 2012

\subsection{Accessibility isochronal analysis}

To analyze the spatial distribution characteristics and differences of accessibility, we used a global accessibility graph to generate an isochrome map with several contours and time values of $0.25,0.5,1,1.5$ and $2 \mathrm{~h}$, respectively (see Figure 4 ). The contour lines follow a concentric pattern. A single contour may appear obviously stretched owing to the influence of divergent expressways and subway lines. The spatial distribution of the $0.25 \mathrm{~h}$ contour is the same as that of the Second Ring Road. This contour extended along subway Line 1 in the east-west direction, and along subways Line 4 and Line 5 in the north-south direction. 


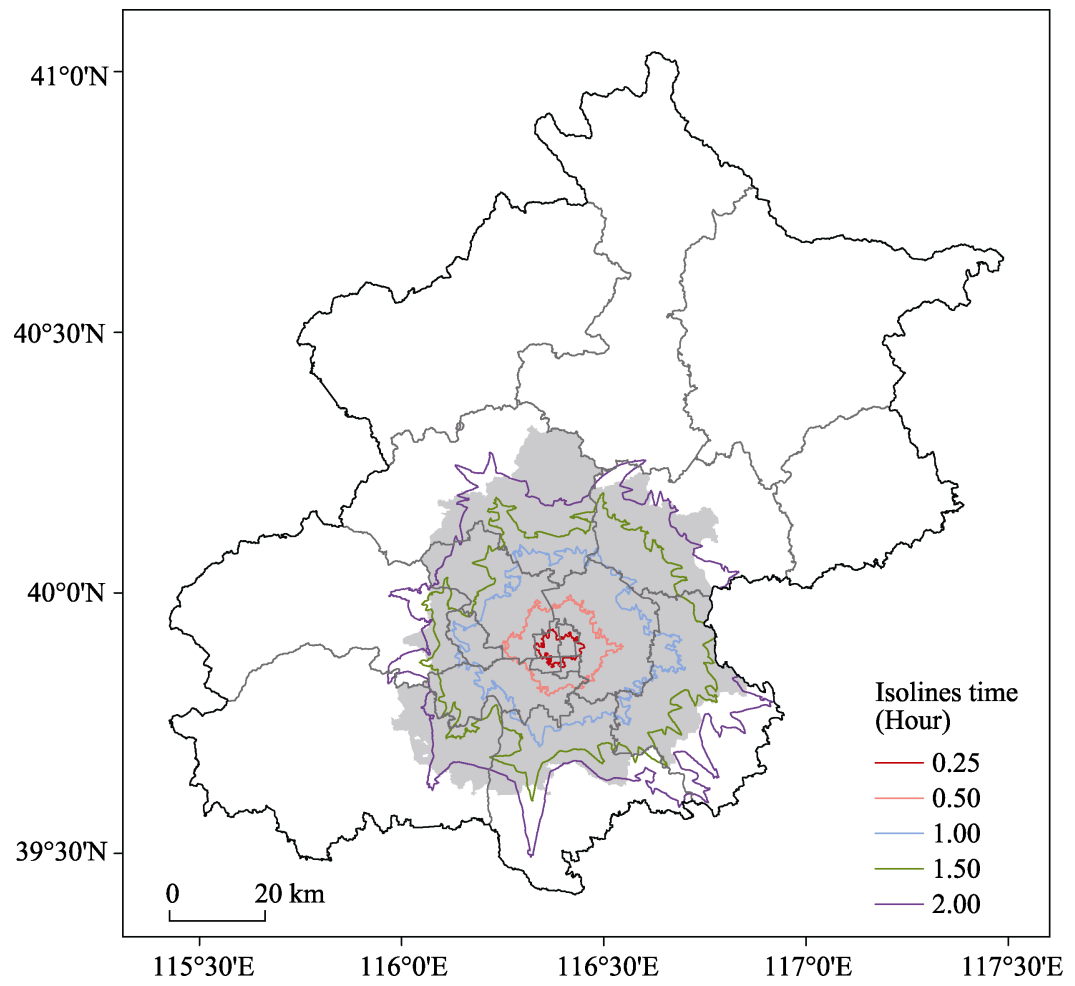

Figure 4 Isolines of time accessibility of Beijing urban area in 2012

The spatial pattern of accessibility is influenced by the subway distribution, and its coverage is narrow. Accordingly, in the north-south direction, the $0.25 \mathrm{~h}$ contour line shows a significant depression between subways Line 4 and Line 5, which may be interpreted as evidence of the subway's contribution to accessibility. The Fourth Ring Road and the $0.5 \mathrm{~h}$ contour line share approximately the same spatial layout. Influenced by the subway lines and the city divergent expressway, the Fourth Ring Road follows a rounder line than the $0.25 \mathrm{~h}$ contour line, which is also due to the gradual increase of the radial road. The $1 \mathrm{~h}$ contour line encompasses almost the entire Beijing subway system, except for the airport line, the northern terminus of subway line No. 5 (Tiantongyuan), the western terminus of Line 1 (Pingguoyuan), the eastern terminus of the Batong Line (Tuqiao) and the northern terminus of Line 4 (Anheqiao). The southern end of the $1 \mathrm{~h}$ contour line thus is not influenced by the subway, whose spatial outlay basically covers the same areas as the southern Fifth Ring Road. In contrast, in the NUA of Beijing, as a result of Line 13, Line 4, Line 5 and the Airport Line, the northern extremity of the contour line lies beyond the northern segment of the Fifth Ring Road. This difference highlights the characteristics of the infrastructure of the NUA of Beijing, especially the impact of rail transit construction on the regional development environment. It also explains why Beijing residents prefer to settle in the northern part of the city. The trend of the $1.5 \mathrm{~h}$ contour line approximately follows that of the Sixth Ring Road. The main areas of difference are directional tensions along certain expressways, while other areas display depressions. The $2 \mathrm{~h}$ contour line was scattered around the peripheral parts of the study area, and extends only a limited distance beyond the $1.5 \mathrm{~h}$ contour line. 
There is strong consistency between each time contour and the lines of the city ring roads, with the exception of the difference between the $1 \mathrm{~h}$ contour and the Fifth Ring Road. The coverage areas of the $0.25,0.5$, and $1.5 \mathrm{~h}$ contour lines closely approximate those of the Second Ring Road, Fourth Ring Road and Sixth Ring Road, respectively. The northern ends of subways Line 13, Line 4 and Line 5 considerably extend the northern extremity of the $1 \mathrm{~h}$ contour line, while Line 1 and the Batong Line have the same effect on their respective eastern end. Other regions overlap well and consequently the coverage of the $1 \mathrm{~h}$ contour line is nearly twice that of the Fifth Ring Road. The same time line is many times longer than the loop length, because from the micro perspective, the types, levels and distribution difference of the traffic infrastructure caused the difference in accessibility, creating the contour of a roundabout with wrinkles. The spatial distributions of temporal contour lines characterize the farthest distance that can be reached in a given time. Here we study the spatial distribution of the contour lines to identify the main regions traversed by the lines, as shown in Table 3.

Table 3 Isotime's attribute and its relationship with city expressways and geographic locations

\begin{tabular}{lccccc}
\hline & Length $(\mathrm{km})$ & Area $\left(\mathrm{km}^{2}\right)$ & \multicolumn{3}{c}{ The attribute of ring road nearby } \\
\cline { 4 - 6 } & & & Name & Length $(\mathrm{km})$ & Area $^{(\mathrm{km})}$ \\
\hline 0.25 h Isotime line & 64.37 & 46.94 & Second Ring Road & 32.70 & 61.54 \\
0.5 h Isotime line & 154.40 & 279.43 & Fourth Ring Road & 65.30 & 304.95 \\
1.0 h Isotime line & 319.16 & 1150.31 & Fifth Ring Road & 98.58 & 667.63 \\
1.5 h Isotime line & 372.75 & 2182.76 & Sixth Ring Road & 187.50 & 2269.27 \\
\hline
\end{tabular}

\subsection{Time accessibility and road density distribution}

To investigate the relationship between time accessibility and infrastructure construction, the township-level (or street-level) road densities were calculated, as shown in Figure 5. The formula is as follows: $\rho=d / s$, where $\rho$ denotes the density value of township roads, $d$ is the total length of the township roads, and $s$ is the area of the administrative township divisions. The area with the highest township road density is the Wanliu Land Plot of Haidian District, with a road density of 109.30. Meanwhile, the area with the lowest density of township roads is Xingshou Town in Changping District, which has a road density of only 0.18 . Owing to zoning adjustment, the administrative area of Wanliu is only $0.2 \mathrm{~km}^{2}$, having exaggerated road density. Xingshou town is located outside the Sixth Ring Road, and is not located near other high-speed roads, so its road density is much lower. Using the Nature Break method to measure road density, the various areas surveyed can be divided into four grades based on the road density assessment results (Figure 5). The first grade comprises 10 villages and townships (or street-level), three of which belong to the SUA. Meanwhile, the NUA has seven villages and towns. The second grade includes a total of 34 villages and towns, of which the SUA contains 16 and the NUA contains 18, accounting for 47.06 and $52.94 \%$ of the total, respectively. The third grade contains a total of 59 villages and towns, of which the SUA has 11 and the NUA has 48 , accounting for $18.64 \%$ and $81.36 \%$ of the total, respectively. The fourth grade contains a total of 59 villages and towns, of which the SUA has 24 (40.68\%), while the NUA contains 35 (59.32\%). Overall, road density in Beijing displays a similar pattern to time accessibility, namely gradual peripheral decay. The 
road density in Beijing's core functional area significantly exceeded that in its outlying townships. Furthermore, infrastructure construction differed substantially between the NUA and SUA. In the SUA, the first to third grade road density of townships accounts for 55.56\% of the total region's area, while in the NUA, the equivalent figure is $67.59 \%$ (Figure 6).

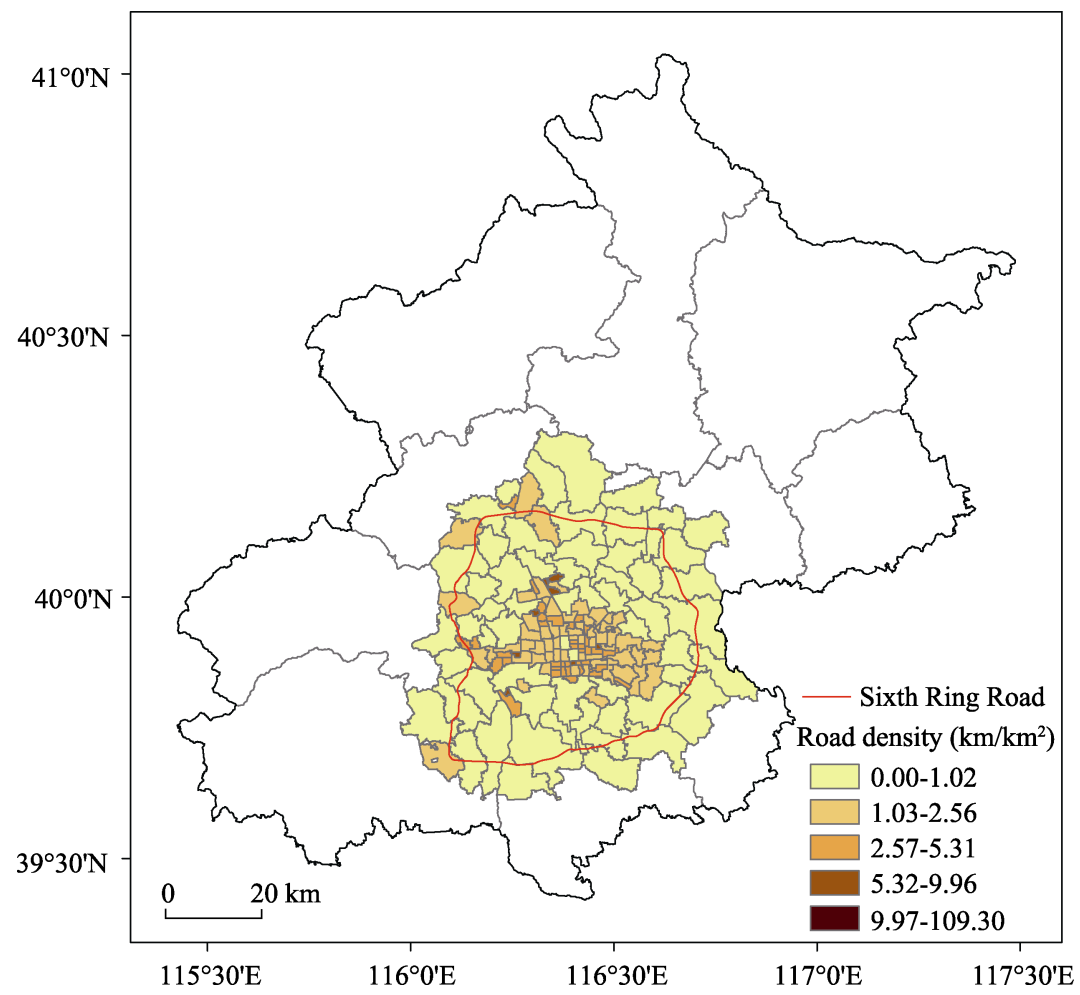

Figure 5 Road density in the study area of Beijing in 2012

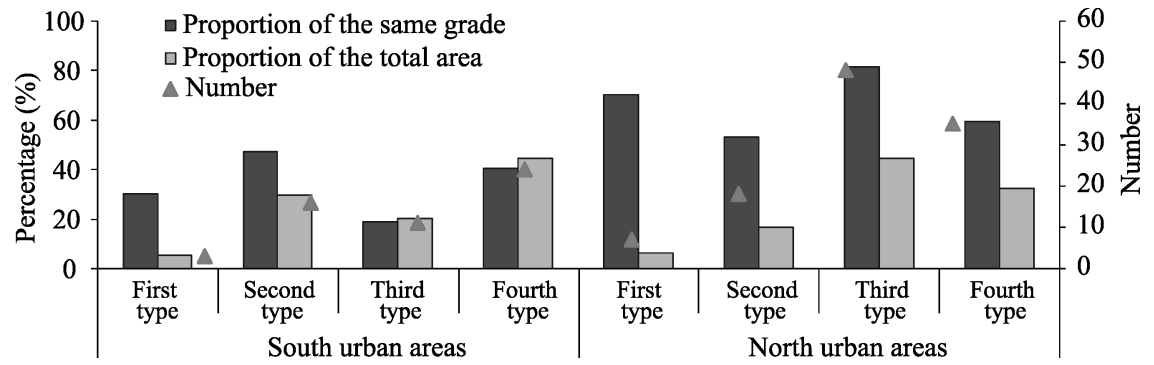

Figure 6 Comparison of road density in the north and south parts of urban Beijing

Taking road density as the abscissa and time accessibility as the ordinate, we generate a scatterplot of the study area, as shown in Figure 7. We selected 1 and 0.8 as the high and low thresholds for road density and time accessibility, allowing the classification of townships into four types by combining any two. The four types are as follows: (1) $(\rho \geqslant 1 \& T \geqslant 0.8)$, good internal road infrastructure but poor accessibility to the center; $(2)(\rho<1 \& T \geqslant 0.8)$, poor road infrastructure and poor accessibility to the center; (3) $(\rho<1 \& T<0.8)$, poor road infrastructure but good accessibility to the center; (4) $(\rho \geqslant 1 \& T<0.8)$, good internal road infra- 
structure and good accessibility to the center.

As shown in Figure 8, the first type of units (towns, townships, streets) are all distributed outside the Fifth Ring Road and contain no subway stations, so time accessibility is poor. However, as units in this type are distributed along the city's main highways and high-speed roads, and are mostly located in the centers of towns and suburban districts in Beijing. The relative complete urban road construction makes the road density value relatively high. The second type of units is widely distributed outside the Fifth Ring Road. Far from the downtown districts and county centers, both time accessibility and road density values are low for these townships. The third type of units is mainly distributed within or along the Fifth Ring Road, and is mostly located around subway stations, and hence has good accessibility. However, road infrastructure construction in these locations is still inadequate compared with those in city center, so these locations have good accessibility and low road density. Notably, Donghua Gate Street is an example of a street that is located in the center of

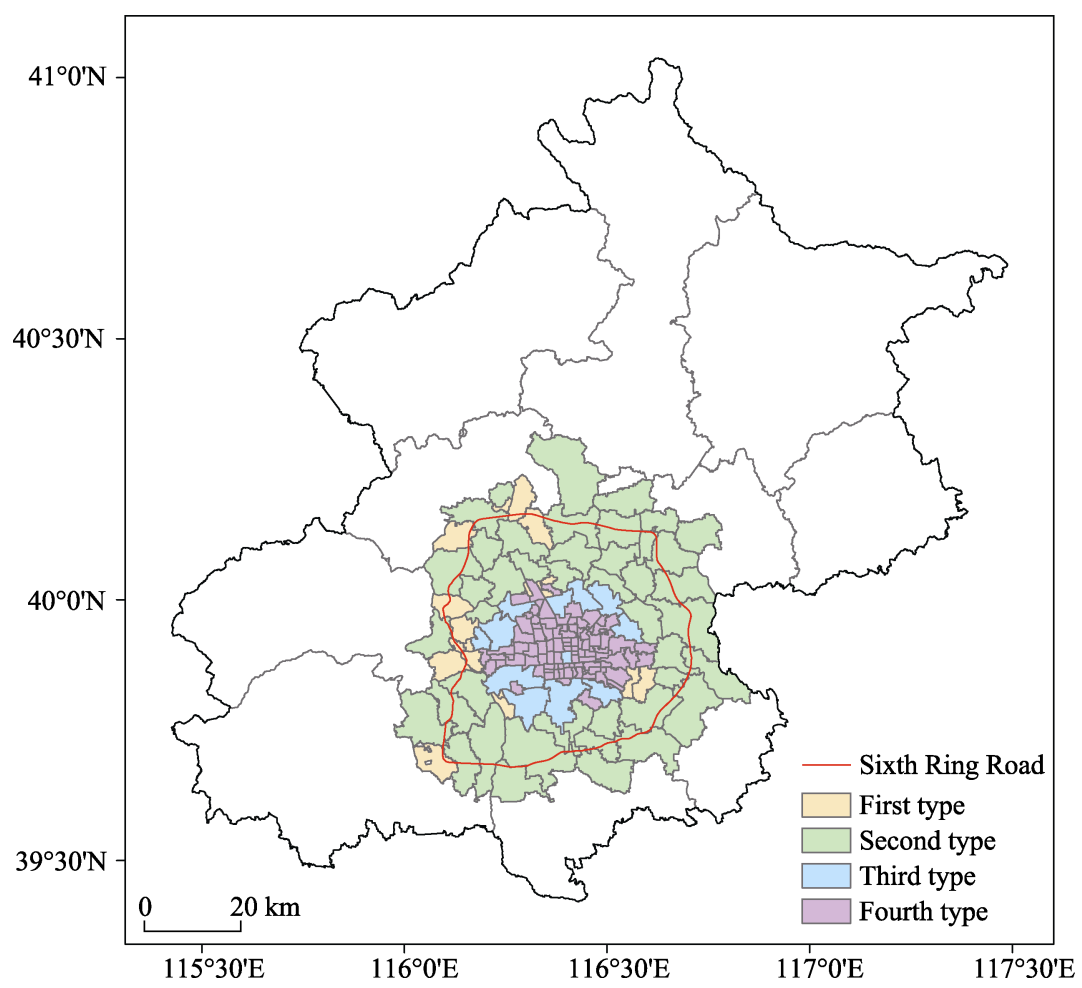

Figure 8 Spatial distribution of different types of units in Beijing in 2012 
Beijing, but the area also includes the Forbidden City, Tiananmen Square and other large protected areas, all of which limit city construction according to policy restrictions. The fourth type of units is concentrated in the city center and near subway lines. The core area of the city has superior road infrastructure, and the convenient rail transportation considerably reduces commuting time. Such areas mainly extend along subway Line 1 and display consistency in their east-west extension. Conversely, the distribution difference is large in the north-south direction, and that in the southern extension is especially obvious. Taking subway Line 1 as the boundary, further investigations were conducted for the distribution numbers and areas, and revealed that the NUA and SUA differ significantly in terms of accessibility and road infrastructure construction (Figure 8).

The numbers of units belonging to the first type in the SUA and NUA are 6 and 12, respectively, accounting for $11.11 \%$ and $11.21 \%$ of the total number of units in their respective region, and $7.78 \%$ and $10.34 \%$ of the total area of each region. The difference between the SUA and NUA in terms of this type of units is not big, but this may also reflect the differences in spatial disparity between the two regions. The numbers of the second type of units in the SUA and NUA are 19 and 25, respectively, accounting for $35.19 \%$ and $23.36 \%$ of the total number of units in each region, and $75.53 \%$ and $64.27 \%$ of the total area of each region. In the SUA, units belonging to the second type comprise $75.53 \%$ of the total number, which reflects infrastructure construction in large swathes of the southern part lagging behind that in the northern under poor accessibility conditions. The number of units belonging to the third type are 4 and 8 in the SUA and NUA, respectively, accounting for $7.41 \%$ and $7.48 \%$ of the total number of units in each region, and $10.66 \%$ and $8.95 \%$ of the total area of each region. Additionally, in terms of area, units of the third type occupy nearly $1.5 \%$ more of the SUA than the NUA, highlighting the poor condition of infrastructure construction. Such units are mainly distributed in the SUA, because this region is linked to the city center by few subway stations. However, improvement is needed in overall road construction in this part of the city. The numbers of the fourth type of units in the NUA and the SUA are 25 and 62 , respectively, accounting for $46.30 \%$ and $57.94 \%$ of the total number in each region, and $6.03 \%$ and $16.44 \%$ of the total area. The accessibility of the SUA is poor and good road facilities in the SUA lag behind those for the whole study area by nearly 10 percentage points. The distribution pattern of the units exhibits a concave pattern in the NUA and a convex pattern in the SUA, with these patterns following the subways in each case (Figure 9).

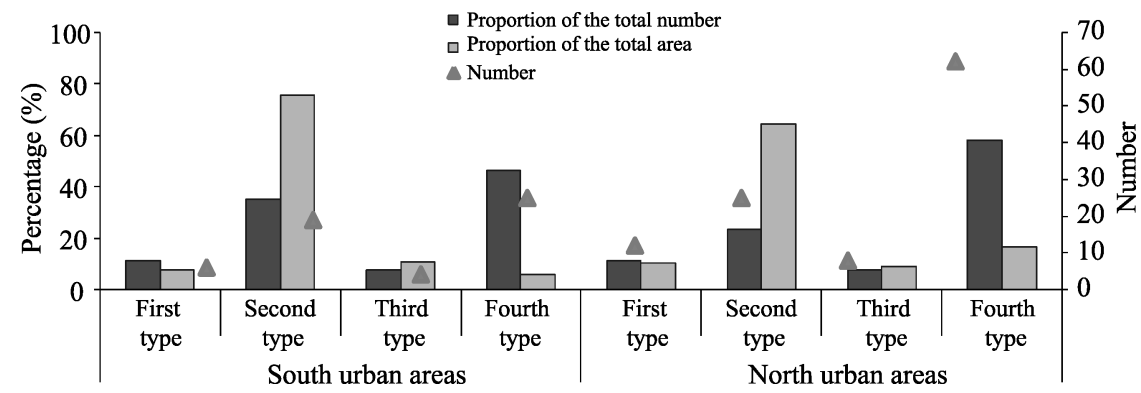

Figure 9 Comparison of different types of units between the northern and southern urban areas 


\subsection{Analysis of urban land partition}

Location factors are closely linked to the value of urban land ( $\mathrm{Du}$ and $\mathrm{Xu}, 1997)$, with location being the factor affecting land plot value (Northam, 1978). According to geographical scale and regional heterogeneity, location factors can be divided into macro-location factors, meso-location factors and micro-location factors. Macro-location factors relate to the accessibility between a city and its surrounding areas as well as external links, and denote the positioning of urban location on a national or inter-regional scale. Meso-location factors denote the difficulty of reaching the city center from each area of a large city, and are especially important for a single-center city with super agglomeration. Micro-location factors denote the convenience of reaching the micro-geographical area from adjacent areas. Road intensity is an important indicator of traffic conditions. Generally, road density represents the complete extent of regional basic infrastructure construction, as well as the convenience of traffic condition, and thus characterizes microscopic location factors. This study takes Beijing city proper as the study area, and so meso- and micro-scale studies are more suitable, which should primarily be considered the meso- and micro-location factors that affect the level of the premium and decide land use efficiency, including characterization using time accessibility and road density. Based on the two indexes, starting from the different types of regional areas, this study analyzed the relationship between land use efficiency and location factors, identified the regional difference of location factors of land use efficiency and explained their causes. This study thus provides a scientific basis for future urban planning and road system construction for Beijing.

According to regional road density and time accessibility, we perform comprehensive division and measure the relationships between the land price and the two major indicators in different types of regions that are divided by road density and time accessibility, as shown in Table 4. The land price of the first type of the region is significantly correlated with the first class road density, and the correlation with time accessibility to the city center is not significant. The first type of the region is Beijing New City, within the Sixth Ring Road, which has excellent public services that are second only to those in the city center, making the premium level and micro-regional factors more relevant. To some extent, this study also proved that urban land price does not necessarily decrease with increasing distance from the center, and confirms the reasonable premium decay curve of the "wave" and "tail" phenomenon from the regional perspective. As we continue to improve commuting time between the center and the new suburban areas, we should attach more importance to micro-scale regional construction such as new infrastructure and public services. Such an approach gives full play to the function of the new city in undertaking industrial transfer, as well as population agglomeration, ecological construction and improvement of the radiation capacity of the subway system and relief of the central pressures of urban employment, transportation and public service. Land price for the second type of the region and time accessibility are negatively correlated, but the correlation coefficient for minimum absolute value is the lowest among the four types. Additionally, land price and road density have no significant correlation. The second type of the region is widely distributed outside the Fifth Ring Road, and sufficient land supply has made this area the main focus of exploration. According to statistics, of the 415 plots sold since 2008 in the study area, $75.9 \%$ were located 
in the second type of the region. Additionally, up to $61 \%$ of residential land and $95 \%$ of industrial land are located in this region, and therefore we can say that land development in Beijing city proper is gradually entering the fifth ring. As the political and cultural center of China, the economy of Beijing is growing around $10 \%$ annually and its resident population is increasing at a rate of 604,000 people per year. In the midst of this growth, land resources remain the foundation of all economic and social activities. When improving the accessibility of this region and the city center, we should take strategic advantage of industrial structure upgrading, pay attention to the investment direction and intensity of land factors, and avoid the weird cycle of "living unipolar development" and "traditional industry extensive expansion". Conversely, we should advocate the development route of supporting infrastructure construction, and of coordinating population growth with industry at the regional level.

Table 4 Regression analysis of land price by different typologies

\begin{tabular}{|c|c|c|c|c|c|c|c|}
\hline & \multicolumn{4}{|c|}{ Land price sample } & \multicolumn{3}{|c|}{ Regression equation } \\
\hline & Commercial & Residential & Industrial & Total & Road density & Time accessibility & $\mathrm{R}^{2}$ \\
\hline First type region & 3 & 6 & 7 & 16 & $0.265 * *$ & 0.065 & 0.484 \\
\hline Second type region & 45 & 80 & 190 & 315 & -0.133 & $-0.355^{* *}$ & 0.230 \\
\hline Third type region & 15 & 21 & 2 & 38 & 0.598 & $-1.410^{*}$ & 0.217 \\
\hline Fourth type region & 22 & 24 & 0 & 46 & -0.206 & $-5.524 * *$ & 0.395 \\
\hline
\end{tabular}

Note: ${ }^{*}$ denotes 0.1 significant level; ${ }^{* *} 0.1$ significant level; the remaining, non-significant.

\section{Conclusions and discussion}

Some conclusions can be drawn as follows.

(1) The obvious "core-periphery" model can be solved by analyzing the current spatial structure of accessibility in the streets. Some differences can also be seen in the spatial structure of accessibility. Taking subway Line 1 as the boundary, the NUA has superior accessibility to the SUA, mainly because metro line distribution is denser in the north.

(2) Time contours largely coincide with urban loops. The $0.25,0.5$ and $1.5 \mathrm{~h}$ contour lines coincide with subway Line 2, Line 4 and Line 6 , respectively. The exception to this pattern is the $1 \mathrm{~h}$ contour line.

(3) According to composite indicators, including road density and time accessibility, the townships (streets) can be divided into four types. The first type units are mainly located in central city areas with relatively high road density located in suburban counties; the second type are located far from the city center and district centers and account for $75.53 \%$ of the SUA. This means that the infrastructure of southern Beijing lags behind that of northern Beijing. The range with good accessibility is $10 \%$ larger in area in northern Beijing than in southern Beijing.

(4) Based on the division of the four types of townships and the data for land market transactions in Beijing for the entire sample area since 2008, the differences in the relationship between land use types and land-effectiveness and geographical factors among the four regions are revealed, and provide a reference for construction planning in different regions. 
Regarding the first type, regional infrastructure is a priority in terms of reducing the pressure of traffic, public service and employment in central Beijing. For the second type of region, industrial and residential layouts should be strengthened. In the third type, accessibility to the city center should be strengthened to alleviate tidal employment commuter population pressure. Finally, the priority for the fourth type lies in rational planning of commercial land.

The implementation of "the adjustment of the capital core function area", continuously encrypted subway lines and "promotion of the city's southern regions to accelerate the development of the Action Plan", will further improve and optimize time accessibility in Beijing. Meanwhile, infrastructure differences between the SUA and NUA will be gradually diminished. The integrated assessment model has a significant advantage in understanding spatial features of time accessibility and in dividing regional patterns based on composite indicators, including time accessibility and road density. The adjustment of urban spatial structure induced by transport infrastructure construction will be the focus of future research.

\section{References}

Bowen J, 2000. Airline hubs in Southeast Asia: National economic development and nodal accessibility. Journal of Transport Geography, 8(1): 25-41.

Bruinsma F R, Rietveld P, 1993. Urban agglomerations in European infrastructure networks. Urban Studies, 30(6): 919-934.

Cao X S, Yan X P, 2003. The impact of the evolution of land network on spatial structure of accessibility in the developed areas: The case of Dongguan city in Guangdong province. Geographical Research, 22(3): 305-312. (in Chinese)

Du D B, Xu J G, 1997. An analysis on location factors affecting the spatial distribution of Shanghai land value. Acta Geographica Sinica, 52(5): 403-412. (in Chinese)

Dupuy G, Stransky V, 1996. Cities and highway network in Europe. Journal of Transport Geography, 4(2): $107-121$.

Geertman S C M, Ritsema van Eck J R, 1995. GIS and models of accessibility potential: An application in planning. International Journal of Geographical Information Systems, 9(1): 67-80.

Gutiérrez J, 2001. Location, economic potential and daily accessibility: An analysis of the accessibility impact of the high-speed line Madrid-Barcelona-French border. Journal of Transport Geography, 9(4): $229-242$.

Gutiérrez J, González R, Gómez G, 1996. The European high speed train network: Predicted effects on accessibility patterns. Journal of Transport Geography, 4(4): 227-38.

Gutiérrez J, Urbano P, 1996. Accessibility in the European Union: The impact of the trans-European road network. Journal of Transport Geography, 4(1): 15-25.

Jiang H B, Xu J G, Qi Y, 2010. The influence of Beijing-Shanghai high-speed railways on land accessibility of regional center cities. Acta Geographica Sinica, 65(10): 1287-1298. (in Chinese)

Jin C, Lu Y Q, Zhang L, Xu J, 2009. An analysis of accessibility of scenic spots based on land traffic network: A case study of Nanjing. Geographical Research, 28(1): 246-258. (in Chinese)

Jin F J, Wang J E, 2004. Railway network expansion and spatial accessibility analysis in China: 1906-2000. Acta Geographica Sinica, 59(2): 293-302. (in Chinese)

Keeble D, Offord J, Walker S, 1988. Peripheral Regions in a Community of Twelve Member States. Luxembourg/Washington DC: Office for Official Publications of the European Communities.

Li P H, Lu Y Q, 2001. Metropolitan accessibility: Literature review and research progress in the west. Urban Problems, 123: 69-73. (in Chinese) 
Li S M, Shum Y M, 2001. Impacts of the National Trunk Highway System on accessibility in China. Journal of Transport Geography, 9(1): 39-48.

Lie W, Shao C F, 2008. Research on accessibility calculating method of regional transportation. Technology \& Economy in Areas of Communications, 10(4): 85-87. (in Chinese)

Linneker B J, Spence N A, 1992. Accessibility measures compared in an analysis of the impact of the M25 London Orbital Motorway on Britain. Environment and Planning A, 24(8): 1137-1154.

Linneker B, Spence N, 1996. Road transport infrastructure and regional economic development: The regional development effects of the M25 London orbital motorway. Journal of Transport Geography, 4(2): 77-92.

Lutter H, Pütz T, Spangenberg M, 1992. Accessibility and Peripherality of Community Regions: The Role of Road Long Distance Railway and Airport Networks. Brussels: Commission of the European Communities.

Murayama Y, 1994. The impact of railways on accessibility in the Japanese urban system. Journal of Transport Geography, 2(2): 87-101.

Nong X Z, 2003. The choice of the highest train speed in Guangzhou Metro Line 3. Urban Mass Transit, 6(3): 83-88. (in Chinese)

Northam R M, 1978. Urban Geography. New York: John Wiley Sons.

Reng F T, Liu X M, Rong J et al., 2003. Traffic Engineering. Beijing: China Communications Press. (in Chinese)

Shi Z H, Zhou, Q R, Zheng X W et al., 2003. Code for Design of Metro (GB50157-2003). Beijing Urban Engineering Design and Research Institute. (in Chinese)

Spence N, Linneker B, 1994. Evolution of the motorway network and changing levels of accessibility in Great Britain. Journal of Transport Geography, 2(4): 247-264.

Wei L H, Cong Y G, 2004. The influence of inter-cities express passenger train on spatial structure of metropolitan area: A case of Jingjintang. Economic Geography, 24(6): 834-837. (in Chinese)

Xu L, Yang X K, Ai S B et al., 2008. Study the service level of the city roads in Beijing. Traffic \& Transportation, 5: 43-45. (in Chinese)

Yang S H, Chen Y Y, Cheng P et al., 2004. Technical Standard of Highway Engineering of China (JTGB01-2003). Ministry of Communications of the People's Republic of China. (in Chinese)

Zhang L, Lu Y Q, 2006. Assessment on regional accessibility based on land transportation network: A case study of the Yangtze River Delta. Acta Geographica Sinica, 61(12): 1235-1246. (in Chinese) 